\title{
Features of Pedagogical Management in the Professional Activity of the Future Teachers
}

\section{Pirmaganbet Ishanov}

\author{
Candidate of Pedagogical Sciences, Associate Professor, Karaganda State University named after E.A.Buketov \\ ishanov65@mail.ru \\ Gulya Khairova \\ Candidate of Philological Sciences, Associate Professor, Karaganda State University named after E.A.Buketov \\ g.khairova@mail.ru \\ Rustemova Zhanar
}

Candidate of Philological Sciences, Associate Professor, Karaganda State University named after E.A.Buketov

\section{Zhunusova Nailya}

Senior Teacher,Karaganda State University named after E.A.Buketov

\author{
Doi:10.5901/mjss.2015.v6n4s1p57
}

\section{Abstract}

The article discusses the education as a continuous, flexible, goal-oriented process of learning throughout life and that the high quality of education, which depends on the management, determines its effective functioning. Pedagogical systems operate and do not develop spontaneously. Occurring in these changes is due to the ordered pattern management. The ordering of structural and functional components, their integration and interaction with the environment can be provided by private bodies and mechanisms of control. In this sense, the pedagogical system is a system of self-managed. The problem of efficiency of formation of managerial competence of future teachers of physical culture and sports in educational management as a process is also the subject of our analysis. In order to provide maximum reliability and validity of scientific methods and techniques for the practical implementation of the theoretical promises and ideas in the field of training of teachers of physical culture and sports in educational management, we felt it necessary to characterize a set of principles and functions of pedagogical management. Pedagogical management principles considered by us in accordance with their classification, proposed by VP Simonov. Effective scientific management also provides for the implementation of the principle of its system of selfimprovement based on the achievements of the theory and best practice management. This provision is particularly important at the moment when our society is improving the whole control mechanism at all levels.

Keywords: Global educational space, the system of higher education, process of managing in the educational system, the process of learning, the principles of pedagogical management

\section{Introduction}

Under the conditions of entry into the world educational space is particularly important to improve the system of higher education. Today, education is considered as a continuous, flexible, goal-oriented process of learning throughout life and that the high quality of education, which depends on the management, determines its effective functioning. Appeal to the management and allocation of them among the most important areas of modern scientific thought was the result of the increasing dynamics of the process management in pedagogical systems. The complexity and diversity of this phenomenon identified a variety of approaches to its analysis and interpretation, the need to understand that the theory of management in pedagogical systems requires a holistic study. The first source of ideas about management is a philosophy of ancient China and ancient Greece. G.Gegel one of the first made an attempt to describe the essence of the scientific management "Management - is, first of all, the formal implementation of laws and their maintenance ..." [1, p.314]. In ancient China (Lao Tzu, Confucius, Lun Yu et al.), running - is a set of qualities that should be provided with a ruler, and leadership activities in which these qualities are manifested. In ancient Greece, in contrast to the ancient Chinese management is not seen as the sum of the properties and qualities of the person, and as the ability to 
implementation of a certain way of thinking and acting.

\section{Methodology}

At the end of the XIX century in countries with market economy appears science of administration and gets the name of "management" Engels said that "... the management will have to be in charge of not only individual aspects of social life, but also the whole social life in all its forms, in all directions" [2, p.537], which is also confirmed in the present conditions of society development. However, the nature and purpose of the concept of "management" is defined by the specifics of the control object.

In the New illustrated encyclopedic dictionary it is defined as a function organized systems to ensure the preservation of their particular structure, maintenance of the activity, the implementation of their programs and goals. [3] In the Concise Dictionary of Philosophy management refers to the ability of a material to maintain its qualitative determination to maintain a dynamic equilibrium with the environment, to improve [4].

\section{Research and Results}

Analyzing the etymology of the concept of "management", there are three main points of view from which interpreted the term: 1) consideration of management, as a particular activity, characterized by unity of purpose, certain functional composition, the release of stakeholders; 2) definition of management as of targeting the subject of management on a managed object, resulting in a change of the latter; 3) understanding the running of the interaction between elements, entities, which results in their mutual change [5, pp 62-78].

Despite the various aspects of the base and accented in these definitions is general recognition that management is a special kind of activity, performed to ensure the movement of an object to a specified destination. When covering the various aspects of management must take into account the structural features of systems. System of any complexity can be represented as a specially organized holistic totality less complex parts - subsystems, each of which includes a number of interrelated components. This hierarchy allows you to define the control object for a particular situation. A characteristic feature of governance is that it does not happen in all sorts, but only in complex mobile systems where there is a high degree of causality and continuous transition from one state to another. From a management perspective, educational systems can be structured as follows: the object and subject of management; subject of joint activities; learning objectives and pedagogical means of communication. They are all linked, and none of the elements cannot be excluded from the system so that it does not impact on its life. Isolation of subject and object management as key elements of pedagogical systems is conditional, since any member of the pedagogical process can act as a subject and as object, depending on its vessels to the next higher or downstream in the hierarchical series of levels of management. Moreover, the position of each participant in the learning process as a subject of control is defined by the objectives of the education system, which consists in the conversion of the human object to the subject, in the formation of his active selfreliance and the ability to self-government. The active position of the teacher and the student lies in the fact that each of them to a greater or lesser extent, acts as a subject of management of their own activity and behavior, and other activities.

Pedagogical systems operate and do not develop spontaneously. Occurring in these changes is due to the ordered pattern management. The ordering of structural and functional components, their integration and interaction with the environment can be provided by private bodies and mechanisms of control. In this sense, the pedagogical system is a system of self-managed.

In full measure all the above applies to the training of future teachers of physical education and sport as a pedagogical system, system components are: the purpose of the activities (planned, expected results); stakeholders; object of activity; content of the activity (training, management, and other information); ways of working. From the positions pedagogical management substantive content of the components of the educational system takes on different characteristics, as pedagogical management is a set of principles, methods, organizational forms and processing methods of management of pedagogical process aimed at improving its efficiency.

The problem of efficiency of formation of managerial competence of future teachers of physical culture and sports in educational management as a process is also the subject of our analysis. So now we have found it necessary to consider this important aspect we are studying the problem. The most general provisions of the pedagogical management, is effective at both process control and the process are its laws, including having significance for our problem, it should be noted: focus, optimality, manageability, the correlation manage and control subsystems, the proportionality of production and management. Purposefulness - expresses the relation between the target and the 
activities on its achievement. The objectives for managing should be subject to all the activities necessary for its implementation. Optimality of the control expresses the relation between the results, that is, to control, and the cost of achieving them. Optimal called such management, which ensures that the objectives with minimal labor costs, time, or material and energy resources. Manageability as follows from the regularity of management well known in the law of cybernetics requisite variety, which establishes that diversity (complexity) of the controlling subsystem, must match the diversity (complexity) of the controlled subsystem.

Manageability can be normalized. In the span of control sets the number of employees and departments, which can be subordinated by one head or body control while ensuring good governance. From this regularity number of corollaries follows:

- impossible using simple bodies manage with complex bodies, so the simplification management bodies in the continuous of production complication;

- as the ability to control the management subsystem, ceteris paribus depends on the number of the administrative apparatus, the need to promote optimal staffing levels, as unjustified increasing the administrative apparatus causes superfluous costs and excessive reduction - the weakening manageability as a result decrease in production efficiency;

- in multilevel control systems must be installed optimal number of stages, levels, units, since the unjustified increasing of their number growing the number of the device but reduces its efficiency, in the excessive reduction increases the volume and complexity of management at each stage, there are queues in solving the tasks, reduced handling. The correlation of controlling and controllable subsystems. The essence this regularity is the need to ensure that the management and control subsystems in nature, structure and conditions of work. Any significant change in the structure, character and environment management activities of the object must be accompanied by corresponding changes in the structure and content of management subsystem. There can be no effective control subsystems in general, regardless of the object of management.

Applied to our problem, these patterns can mean the following:

- purposefulness of management causes necessity of subordination of all its substantive and procedural components, organizational and hierarchical structure, development of administrative and pedagogical potential of the teacher of physical culture and sports;

- optimal control means taking into account accumulated experience in the field of organizational and management activities of physical culture and sports, when theoretical and empirical base should increase, not in isolation from it, and in unison, and a logical sequence;

- manageability as pattern management the educational process is the production of statutory regulators, as that may be to develop regulations for the planning and organization of educational and training process in physical education and sports, as well as special administrative body (in conjunction with the regularity of optimality such a body can act not necessarily new, and close to nature already functioning structures, but with the condition of its reorganization);

- the correlation means that the newly created or reorganized structure is to be appropriate to the nature and structure of the professional work of the teacher of Physical Education and Sport (for example, this body should be empowered to organize training courses for teachers to pedagogical management, etc.)

In order to provide maximum reliability and validity of scientific methods and techniques for the practical implementation of the theoretical promises and ideas in the field of training of teachers of physical culture and sports in educational management, we felt it necessary to characterize a set of principles and functions of pedagogical management. Pedagogical management principles considered by us in accordance with their classification, proposed by VP Simonov. According to him, the principles of pedagogical management as a system factor are the basic rules of behavior management entity during its interaction with controlled entities (objects). In the framework of principles of pedagogical management it includes: 1) the principle of humanization, 2) the principle of optimality, 3) the principle of analytic activity of the subject of management, 4) the principle of a concrete goal-setting, 5) the principle of cooperation and division of labor, 6) the principle of the functional approach, 7) the principle of comprehensiveness 8) The principle of the system of self-improvement [6].

Humanization as a principle of scientific organization of labor in the structure and content of educational management is the main condition for the development of abilities of students in an organized pedagogical process. In our case this principle, presenting itself through humanitarization content of education in the modern paradigm of education provides equal partnership subjects as subjects of pedagogical management of interpersonal relations.

The principle of a concrete goal-setting, and as a basis for planning and control is the basis of the content of the 
entire work of the manager at any level of management. Violation of this principle in practice at all times brings education in general a very large educational and social damage. This is was manifested, for example, in such educational and educational and management purposes as "give a complete, one hundred percent performance", "from creative teachers to work creatively team", "teach (for the academic year?!) each student to live, study and work the communist ", etc. Such slogans shaped targets come into serious conflict with the real life and the real possibilities of educational institutions in particular. Guiding bureaucratic structure of the education system especially abused such "goals" in the period before 1985.

In general the principle of purposefulness of pedagogical management for optimal and reflects the reality of social significance and future requirements in their goal setting. Uncertain formulated goal (unnecessarily complicated or simple) at an early stage of the process management is disconcerting, disorienting factor and complicated goal besides unrealistic to achieve. Prospects and social importance of objectives reflect the continuous nature of the progressive movement and the development of a complex educational system.

Optimality as a basic principle of the scientific organization of labor in the structure and content of pedagogical management is the condition necessary and sufficient requirements (regulations, directives), management requirements subject to the activities of the Executive (the optimal number of sections of the work plan, the number of planned activities, etc.). In the teacher's professional activity to this principle ensures consistency requirements studying pedagogical requirements. That is a teacher of physical education and sport should harmonize their requirements for physical activity of their students with the class teacher. It is clear that this coherence should be reflected in the teaching and consolidation of organizational documents, for example, in training programs.

The principle of cooperation and labor division reflects the most important requirements for the management of the manager at any level. Not permissible desire to do all the head: develop a work plan, organize its implementation, sole control and coordinate the activities of all the performers. At such position the initiative and creativity of artist gradually reduced, and the head more and more immersed in the "turnover". Therefore, only relying on Public Organizations for collective creativity and collective intelligence allow the head to implement this very important position. This is especially true in the era of transition and the establishment of democracy and openness in our society in general and in education in particular.

The principle of complexity involves a combination of targeted, functional and line management. System management is unthinkable outside the complex science-based subject-subject of management actions, and this principle is its essence. You cannot, define the goals and objectives of management, to stay at the planning stage activities of subordinates, let all things drift. In practice, unfortunately, there are still instances where the work plan drawn up clearly in the school, from the scientific standpoint, but its implementation phase - the organization implementation of decisions - is overlooked. Notes and other position - a plan laid out, organized its implementation, for example, at the beginning of the school year, and periodically monitor and coordinate the activities of artists leaders forget (do not have time, cannot, etc.). In this case, the principle of comprehensiveness cannot be realized in practice, which leads, in spite of the presence of correctly implemented the first component of pedagogical management, reduce the effectiveness of educational management system as a whole.

Principles of analytical activity of the subject of management - the basic rules, which must adhere to the manager of the educational process by observing, analyzing and evaluating the effectiveness of teachers and students.

\section{Conclusion}

A clear realization of the basic ideas of pedagogical management in practice impossible without implementation of the principle of the functional approach. The implementation of this principle is also a condition of constant development and improvement of management activities on the basis of constant renewal of refinement and specification of functions performers. Job descriptions, work rules, evidence-based requirements for educational activities teachers cannot be frozen once and for all, for many years. Conservatism, template, outdated stereotypes in this important matter generate formalism, which is expressed in the preference for familiar, easy and "friendly" forms of organization (and in fact disorganization) activity, contrary to the spirit and essence of the meaning of its content. Effective scientific management also provides for the implementation of the principle of its system of self-improvement based on the achievements of the theory and best practice management. This provision is particularly important at the moment when our society is improving the whole control mechanism at all levels. Adherence to this principle in its organic unity with all the above, will provide not only the efficiency but also the mobility in the development of innovations and understanding of the importance and value. 


\section{References}

Hegel GV Lectures on the history of philosophy. Kn.2. - SPb .: Nauka, 1994. - 423 p.

Engels Elberfeld speech // K. Marx and F. Engels, Soch. - 2nd ed. - M .: GiPLI, 1955. - V.2. - P.532-554.

New Illustrated Encyclopedic Dictionary. - M: Scientific publishing house "Great Russian Encyclopedia", 1999. - 910p.

Concise Dictionary of Philosophy. - M .: Politizdat, 1982. - 431p.

Afanasiev V. About the integrity of the system // Problems of Philosophy. - 1980. - №6. - P.62-78.

Simonov V.P Teaching Management: 50 know-how in the field of: educational management: Textbook. - M .: Rospedagenstvo, 1997. 264p. 